NASA/TM-2006-214015

\title{
Dual Input AND Gate Fabricated From a Single Channel Poly (3-Hexylthiophene) Thin Film Field Effect Transistor
}

\author{
N.J. Pinto and R. Pérez \\ University of Puerto Rico-Humacao, Humacao, Puerto Rico \\ C.H. Mueller \\ Analex Corporation, Brook Park, Ohio \\ N. Theofylaktos and F.A. Miranda \\ Glenn Research Center, Cleveland, Ohio
}


Since its founding, NASA has been dedicated to the advancement of aeronautics and space science. The NASA Scientific and Technical Information (STI) Program Office plays a key part in helping NASA maintain this important role.

The NASA STI Program Office is operated by Langley Research Center, the Lead Center for NASA's scientific and technical information. The NASA STI Program Office provides access to the NASA STI Database, the largest collection of aeronautical and space science STI in the world. The Program Office is also NASA's institutional mechanism for disseminating the results of its research and development activities. These results are published by NASA in the NASA STI Report Series, which includes the following report types:

- $\quad$ TECHNICAL PUBLICATION. Reports of completed research or a major significant phase of research that present the results of NASA programs and include extensive data or theoretical analysis. Includes compilations of significant scientific and technical data and information deemed to be of continuing reference value. NASA's counterpart of peerreviewed formal professional papers but has less stringent limitations on manuscript length and extent of graphic presentations.

- TECHNICAL MEMORANDUM. Scientific and technical findings that are preliminary or of specialized interest, e.g., quick release reports, working papers, and bibliographies that contain minimal annotation. Does not contain extensive analysis.

- CONTRACTOR REPORT. Scientific and technical findings by NASA-sponsored contractors and grantees.
- CONFERENCE PUBLICATION. Collected papers from scientific and technical conferences, symposia, seminars, or other meetings sponsored or cosponsored by NASA.

- SPECIAL PUBLICATION. Scientific, technical, or historical information from NASA programs, projects, and missions, often concerned with subjects having substantial public interest.

- TECHNICAL TRANSLATION. Englishlanguage translations of foreign scientific and technical material pertinent to NASA's mission.

Specialized services that complement the STI Program Office's diverse offerings include creating custom thesauri, building customized databases, organizing and publishing research results ... even providing videos.

For more information about the NASA STI Program Office, see the following:

- Access the NASA STI Program Home Page at http://www.sti.nasa.gov

- E-mail your question via the Internet to help@sti.nasa.gov

- Fax your question to the NASA Access Help Desk at 301-621-0134

- Telephone the NASA Access Help Desk at 301-621-0390

- Write to:

NASA Access Help Desk

NASA Center for AeroSpace Information 7121 Standard Drive

Hanover, MD 21076 
NASA/TM-2006-214015

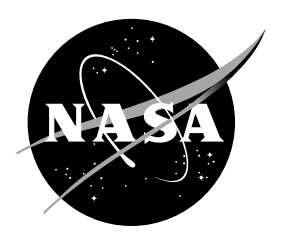

\title{
Dual Input AND Gate Fabricated From a Single Channel Poly (3-Hexylthiophene) Thin Film Field Effect Transistor
}

\author{
N.J. Pinto and R. Pérez \\ University of Puerto Rico-Humacao, Humacao, Puerto Rico \\ C.H. Mueller \\ Analex Corporation, Brook Park, Ohio \\ N.Theofylaktos and F.A. Miranda \\ Glenn Research Center, Cleveland, Ohio
}

National Aeronautics and

Space Administration

Glenn Research Center 


\begin{tabular}{|l|}
\hline $\begin{array}{l}\text { This report contains preliminary } \\
\text { findings, subject to revision as } \\
\text { analysis proceeds. }\end{array}$ \\
\hline
\end{tabular}

Available from

NASA Center for Aerospace Information 7121 Standard Drive

Hanover, MD 21076
National Technical Information Service 5285 Port Royal Road Springfield, VA 22100

Available electronically at http:/ /gltrs.grc.nasa.gov 


\title{
Dual Input AND Gate Fabricated From a Single Channel Poly(3-Hexylthiophene) Thin Film Field Effect Transistor
}

\author{
N.J. Pinto and R. Pérez \\ University of Puerto Rico-Humacao \\ Department of Physics and Electronics \\ Humacao, Puerto Rico 00791 \\ C.H. Mueller \\ Analex Corporation \\ Brook Park, Ohio 44142 \\ N. Theofylaktos and F.A. Miranda \\ National Aeronautics and Space Administration \\ Glenn Research Center \\ Cleveland, Ohio 44135
}

\begin{abstract}
A regio-regular poly(3-hexylthiophene) (RRP3HT) thin film transistor having a split-gate architecture has been fabricated on a doped silicon/silicon nitride substrate and characterized. This device demonstrates AND logic functionality. The device functionality was controlled by applying either 0 or $-10 \mathrm{~V}$ to each of the gate electrodes. When $-10 \mathrm{~V}$ was simultaneously applied to both gates, the device was conductive $(\mathrm{ON})$, while any other combination of gate voltages rendered the device resistive (OFF). The p-type carrier charge mobility was about $5 \times 10^{-4} \mathrm{~cm}^{2} / \mathrm{V}$-s. The low mobility is attributed to the sharp contours of the RRP3HT film due to substrate non-planarity. A significant advantage of this architecture is that AND logic devices with multiple inputs can be fabricated using a single RRP3HT channel with multiple gates.
\end{abstract}

\section{Introduction}

Since the late 1970's, conjugated polymers have been the focus of intense research that has resulted in the synthesis of these polymers having conductivities $(\sigma)$ ranging from the metallic to the insulating regime. The reversible doping and dedoping effects are unique to these systems wherein the conductivity of some polymers can be tuned to any desirable value in the range $10^{-10}<\sigma<10 \mathrm{~s} / \mathrm{cm}$ (ref. 1). While the initial focus was to make these materials have conductivities similar to traditional metals (refs. 2 and 3 ), much of the work has also been aimed at exploiting their semiconducting properties (refs. 4 to 7 ). The delocalize $\pi$-electrons along the polymer backbone are responsible for much of the electronic characteristics exhibited. The inherent material strength together with their electronic properties have made $\pi$-conjugated polymers very promising candidates for use in electronic applications where light weight and flexibility are needed. Semiconducting polymers cannot at present replace inorganic semiconductors based on silicon; nevertheless they are amenable to cheap processing techniques and in large area flexible electronic displays.

Regio-regular poly(3-hexylthiophene) (RRP3HT) is one of the widely studied organic semiconducting polymers (ref. 8) that has a high mobility and ON/OFF ratio when used in a field effect transistor (FET) configuration (refs. 9 and 10), two important device parameters that make it viable for use in practical circuits. This commercially available polymer is also very soluble in common organic solvents and is easily processed to form uniform thin films, making it an attractive candidate for study in research laboratories and in industry. Technologically, the most important polymer-based device 
fabricated and studied is the FET since it forms the basic building block in logic circuits and switches for displays. Figure 1(a) shows a schematic cross-sectional view of the basic FET using an insulating gate dielectric layer over a doped silicon substrate. Two metal leads patterned over the insulator serve as the source and drain terminals of the device while the doped silicon serves as the global gate electrode. To complete the field effect transistor, an organic semiconducting channel is placed between the source and drain terminals either via electrochemical deposition (ref. 4), vacuum deposition (refs. 11 to 13), or spin coating (refs. 7, 9, and 14) of the semiconductor material resulting in a (2D) thin film morphology or via electrospinning resulting in a (1D) nanofibrous morphology (refs. 15 to 17). By connecting individual FET's in tandem several types of logic gates can be fabricated and tested.

In this paper a modified FET architecture has been designed that uses a split gate configuration as shown in the schematic drawing of figure 1(b) so that each gate can be independently addressed. Our previous results on the use of such a design in the case of pentacene have now been extended to RRP3HT (ref. 18). We show that a spin coated RRP3HT single channel split-gate FET functions as a dual input logic AND gate. Since numerous logic circuits that require multiple inputs are widely used in devices such as comparators, the fact that this functionality can be achieved using a single transistor, rather than cascading a series of single input transistors could reduce the number of transistors required in many digital applications thereby making the circuits more compact. We correlate the measured electrical performance of this device with film morphology and substrate design.

\section{Experiment}

\section{A. Substrate Fabrication}

The device substrates were fabricated as follows: The starting wafer was n-type doped $\mathrm{Si}$ $(10 \Omega-\mathrm{cm})$, with a $200 \mathrm{~nm}$ thick thermally grown oxide layer. First, the gate metals, comprised of $20 \mathrm{~nm}$ $\mathrm{Cr} / 100 \mathrm{~nm} \mathrm{Au}$, were vacuum deposited in a thermal evaporator and patterned using conventional photolithographic and liftoff techniques. Next, a $100 \mathrm{~nm}$ thick silicon nitride film, $\mathrm{Si}_{3} \mathrm{~N}_{4}$ (gate dielectric) was deposited over this using chemical vapor deposition (CVD). Access to the gate metallization was obtained by etching windows into the silicon nitride. Figure 2(a) shows an optical image of the substrate prior to deposition of the RRP3HT thin film as seen from the top, where leads ' $a$ ' and ' $b$ ' will correspond to the source and drain terminals, respectively, and leads ' $d$ ' and 'e' will correspond to the two gate electrodes. Electrode 'c' although present was not used. The source and drain metallization also comprised of $20 \mathrm{~nm} \mathrm{Cr} / 100 \mathrm{~nm} \mathrm{Au}$ and was deposited on the CVD grown silicon nitride on either side of the buried split gates using conventional photolithographic and liftoff techniques. The electrode "fingers" were about $20 \mu \mathrm{m}$ wide and $600 \mu \mathrm{m}$ long. The spacing between the electrodes was $\sim 4 \mu \mathrm{m}$. Figure 2(b) shows the image of a similar substrate after spin coating it with a RRP3HT thin film. Due to the complex nature of the substrate fabrication process, the substrate planarity was checked by using an Atomic Force Microscope (AFM). Figure 3 shows an AFM image of a representative mid-section of the substrate prior to the semiconductor deposition, together with a section analysis of the image. As seen in figure 3 , the CVD grown silicon nitride is highly conformal to the substrate topography with sharp edges at the boundaries of the electrodes. The vertical distance between the top of the silicon nitride/gate and the space between the gate and source terminal as indicated by the arrows along the line scan in figure 3 is approximately $125 \mathrm{~nm}$. The mean surface roughness of the silicon nitride dielectric deposited on top of the gate metal was $1.2 \mathrm{~nm}$. This implies that the substrate surface between the source and drain electrodes is not planar, as shown in the schematic representation of figure 1(b). AFM scans were taken in tapping mode using a Digital Instruments NanoScope IIIa Atomic Force Microscope. 

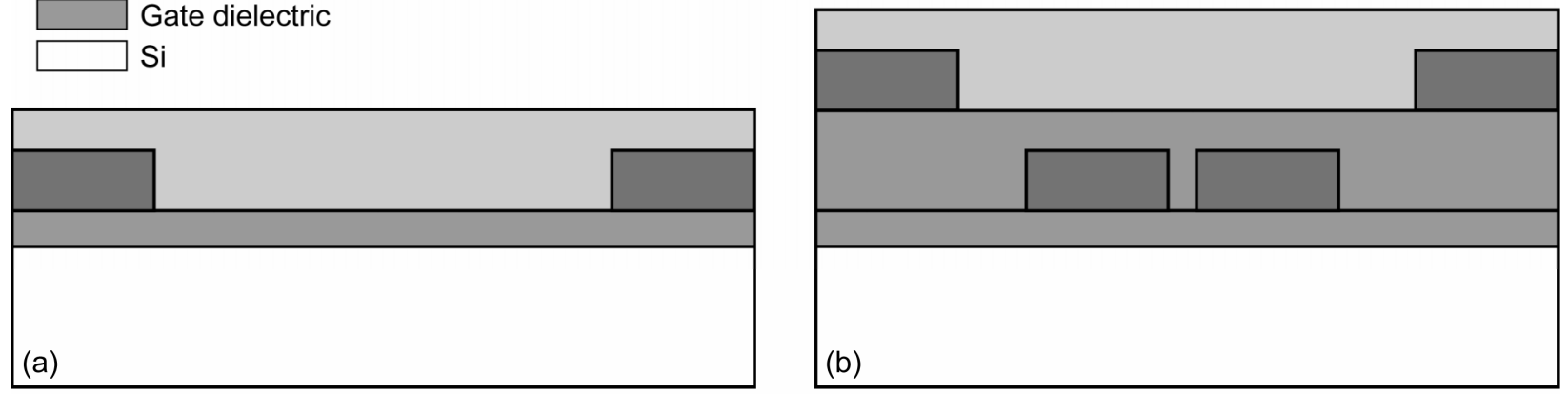

Figure 1.-Schematic cross-sectional view of (a) global gate field effect transistor (b) split gate field effect transistor.
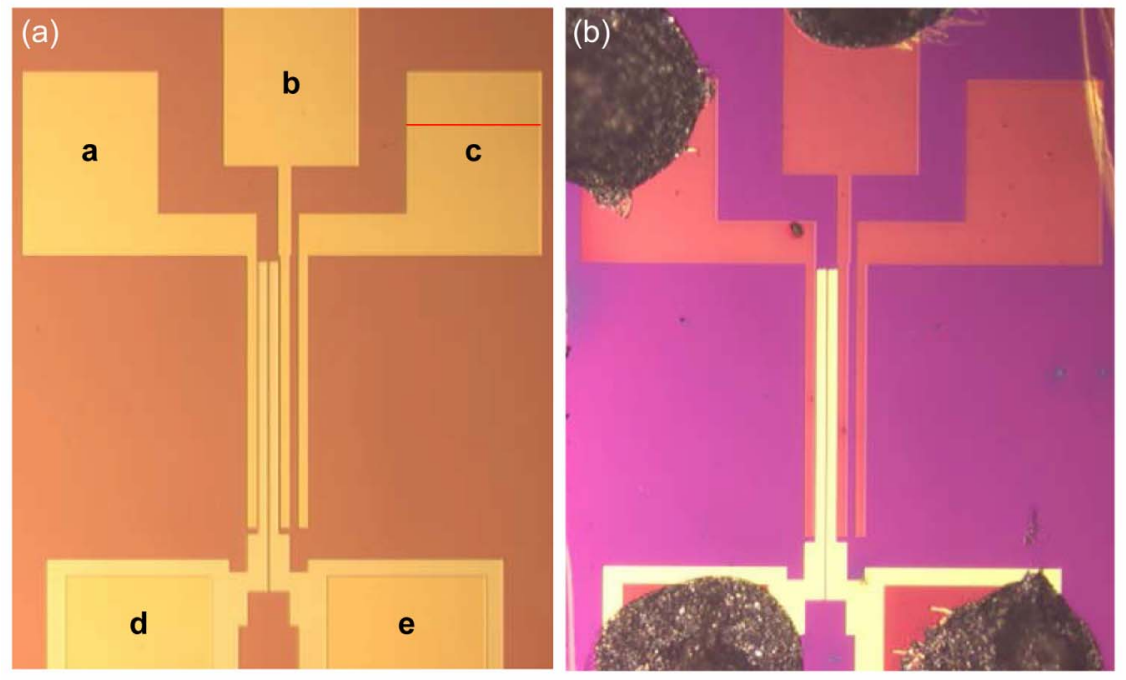

Figure 2.-(Top view-color) Optical images of the device substrate without (left) and with (right) the RRP3HT spun coated layer. The film thickness measured with a profilometer was $\sim 50 \mathrm{~nm}$. Electrodes $\mathbf{a}, \mathbf{b}$ and $\mathbf{c}$ lie on the top of the substrate while electrodes $\mathbf{d}$ and $\mathbf{e}$ are embedded inside the silicon nitride gate dielectric. The silicon nitride was etched to gain access to the gate electrodes. External contacts were made via the use of silver paint as seen in the right side image. Electrodes $\mathbf{a}$ and $\mathbf{b}$ served as the drain and source electrodes respectively while $\mathbf{d}$ and $\mathbf{e}$ were the two gate electrodes. Terminal c was not used. The width of the electrode "fingers" were about $20 \mu \mathrm{m}$ and their lengths were about $600 \mu \mathrm{m}$. The spacing between the electrodes was $\sim 4 \mu \mathrm{m}$. 

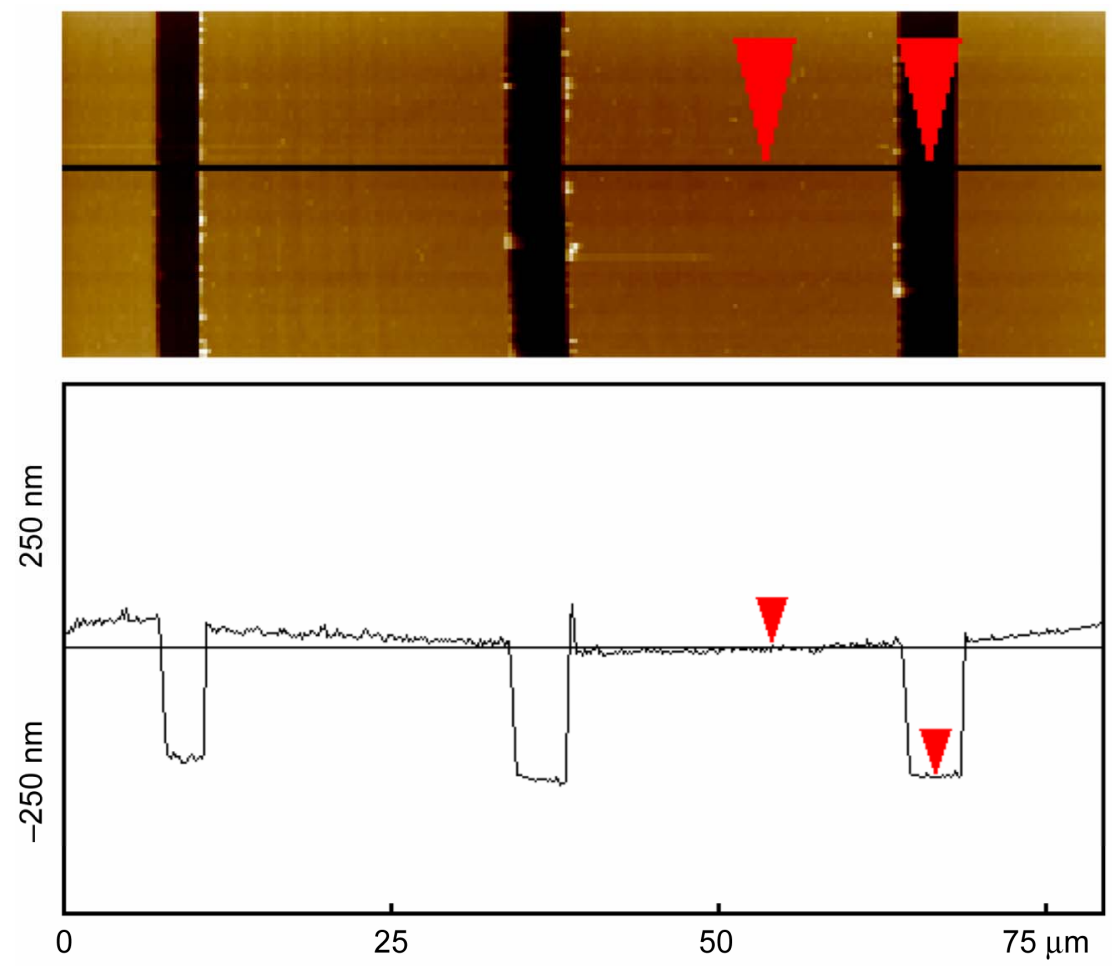

Figure 3.-AFM image of the substrate showing the source, gate and drain regions prior to RRP3HT deposition. The line scan reveals that the silicon nitride gate dielectric is highly conformal to the substrate. The mean surface roughness of the silicon nitride dielectric was $1.2 \mathrm{~nm}$.

\section{B. Thin Film Preparation}

Regio-regular P3HT and chloroform was purchased from Aldrich and used as received. A $0.5 \mathrm{wt} \%$ of RRP3HT was prepared in chloroform and then filtered through a $0.20 \mu \mathrm{m}$ PTFE syringe filter. The substrate with prepatterned leads as described in the previous section was spun in air to $3000 \mathrm{rpm}$ and a drop of the above solution placed over it. The spinning continued for $40 \mathrm{~s}$ and an optically uniform pink film of thickness approximately $50 \mathrm{~nm}$ covered the substrate as seen in figure 2(b). Due to the topography, the thickness of the polymer film can be expected to vary at the top edges and vertical edges of the gate/gate dielectric surface. AFM images of the substrate after RRP3HT deposition were qualitatively similar to figure 3 implying that the polymer conformed to the substrate. The mean surface roughness after RRP3HT deposition was $1.3 \mathrm{~nm}$. The device was then placed in a conventional oven at $50{ }^{\circ} \mathrm{C}$ for 15 minutes after which electrical connections to the contact pads were made with silver paint and gold wire. Once contacted, the device was placed in a vacuum at $5 \times 10^{-4}$ Torr for electrical characterization.

\section{Electrical Characterization}

The electrical drain-source current versus drain-source voltage $\left(I_{D S^{-}} V_{D S}\right)$ characteristics of the device were measured in vacuum using a Keithley model 6517A Electrometer at 296 K. Gate voltages were applied with a Keithley model 6487 picoammeter/voltage source. Measurements were taken with the source electrode grounded; hence the gate 1, gate 2, and drain voltages are referenced to the source. For the logic AND circuit demonstration, a Stanford Research Systems Model DS 335 function generator provided the gate bias, a Tektronix Model TD 3012B digital oscilloscope was used to record the input 
gate bias and a second Keithley model 6517A Electrometer was used to record the output voltage that was measured across a $10 \mathrm{M} \Omega$ load resistor.

\section{Results}

The drain-source current $\left(I_{D S}\right)$ versus drain-source voltage $\left(V_{D S}\right)$ characteristics of the split-gate transistor are shown in figure 4 for various combinations of gate voltages $V_{G S 1}$ and $V_{G S 2}$ which correspond to the voltage applied to the two buried gate electrodes lying in between the drain and source electrodes respectively, as seen in figure 2 . For each scan, the bias on the gate electrodes was either 0 or $-10 \mathrm{~V}$, thus permitting four possible combinations of gate voltages. As seen from this figure, at $V_{D S}=-20 \mathrm{~V}$ the current is significantly higher only when both gate electrodes are biased simultaneously with $-10 \mathrm{~V}$. For the other combinations there was a smaller current primarily due to the intrinsic conductivity of RRP3HT and perhaps due to the unintentional doping in air. Similar results were also seen for other values of common gate bias voltages viz. $I_{D S}$ was higher only when both gates were biased high simultaneously. Thus this device has characteristics similar to a dual input logic AND gate. Due to the uneven substrate topography, especially at the step edges of the gate electrodes, the charge mobility in this device is adversely affected which in turn leads to inferior device characteristics. From figure 4 we can estimate this value from the linear portion of the curves corresponding to the common gate voltages of 0 and $-10 \mathrm{~V}$. The device transconductance $\left(g_{m}\right)$ is given by (refs. 19 and 20 ):

$$
g_{m}=\left.\frac{\partial I_{D S}}{\partial V_{G S}}\right|_{V_{D S}=\text { const }}
$$

Treating the transistor as a single gate structure, with $V_{G S 1}=V_{G S 2}=-10 \mathrm{~V}$ and at $V_{D S}=-1.0 \mathrm{~V}, g_{m}$ is calculated to be $1.60 \times 10^{-11} \mathrm{~s}$. The carrier mobility is then determined using:

$$
\mu=\frac{g_{m} L}{Z C_{i} V_{D}}
$$

where $L$ is the channel length $(40 \mu \mathrm{m}), Z$ is the channel width $(600 \mu \mathrm{m})$, and $C_{i}$ is the capacitance per unit area of the $100 \mathrm{~nm}$ thick silicon nitride layer $\left(6.63 \times 10^{-8} \mathrm{~F} / \mathrm{cm}^{2}\right.$ assuming a dielectric constant of 7.5$)$. In the linear region, the mobility is calculated to be $1.5 \times 10^{-5} \mathrm{~cm}^{2} / \mathrm{V}$-s. The typical mobility of thin film RRRP3HT deposited on planar substrates is falls in the range $10^{-4}-10^{-1} \mathrm{~cm}^{2} / \mathrm{V}$-s (refs. 9 and 10). The low observed mobility is a result of the poor efficiency in charge transport due in part to the rapid evaporation of the solvent during film preparation and due to substrate non-planarity. This substrate non-planarity could lead to associated defects, charge traps and self localization of charge that act as barriers to charge transport.

In order to further characterize the device, a series of measurements having both gates biased with a common voltage has been done. Figure 5 shows the characteristic curves of this experiment. At low drain source voltages the channel current is linear but at voltages comparable to and larger than the gate-source bias, the drain-source current begins to saturate which is typical for polymer-based field effect transistors. True saturation is not seen in this particular device although it has been seen in other RRP3HT devices with split gate electrode configuration prepared under similar conditions. One reason could be the microscopic nature of the polymer contact with the gate dielectric and the conductivity of the polymer due to unintentional doping of the polymer while handled in air, which has been shown to have a detrimental effect on the FET behavior in RRP3HT (ref. 21). As seen in figure 5, the increase in $I_{D S}$ for fixed $V_{D S}$ upon increasing the negative gate bias demonstrates that the device operates as a FET and that the majority carriers are holes. At applied gate biases of $-14 \mathrm{~V}$ on both gates, the ON/OFF ratio of this device was calculated to be $\sim 30$. The conductivity of the film in vacuum was found to be $4 \times 10^{-8} \mathrm{~s} / \mathrm{cm}$ under no 


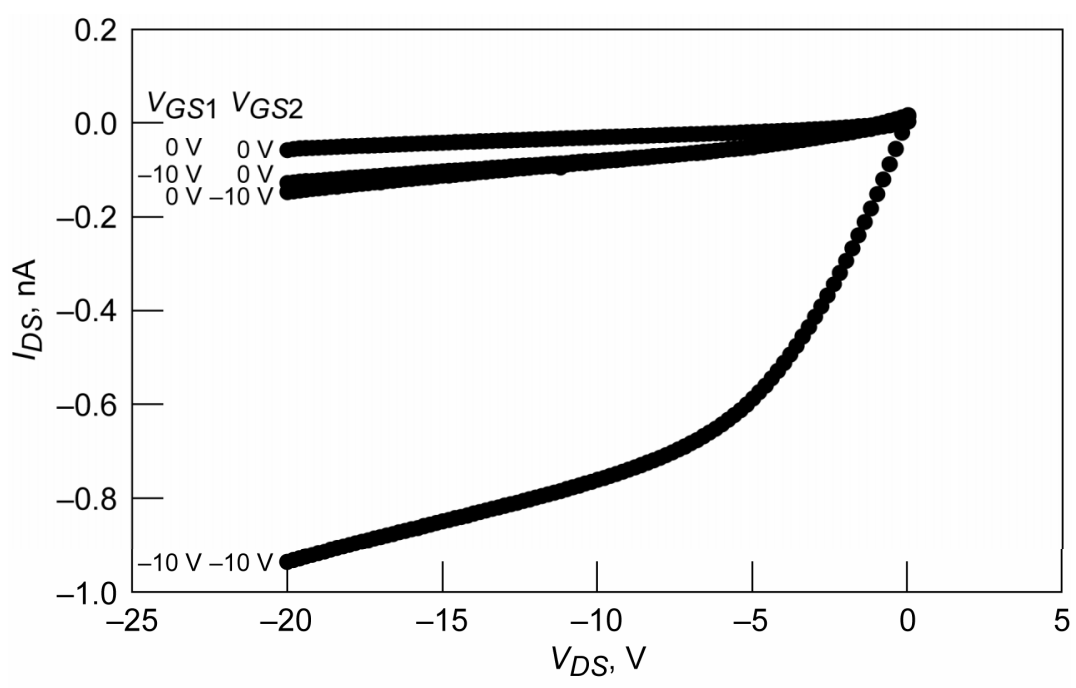

Figure 4.-Drain-source current versus drain-source voltage

$\left(I_{D S}-V_{D S}\right)$ characteristics of the split gate field effect transistor, where the gate-source voltages $\left(V_{G S 1}\right.$ and $\left.V_{G S 2}\right)$ are as indicated.

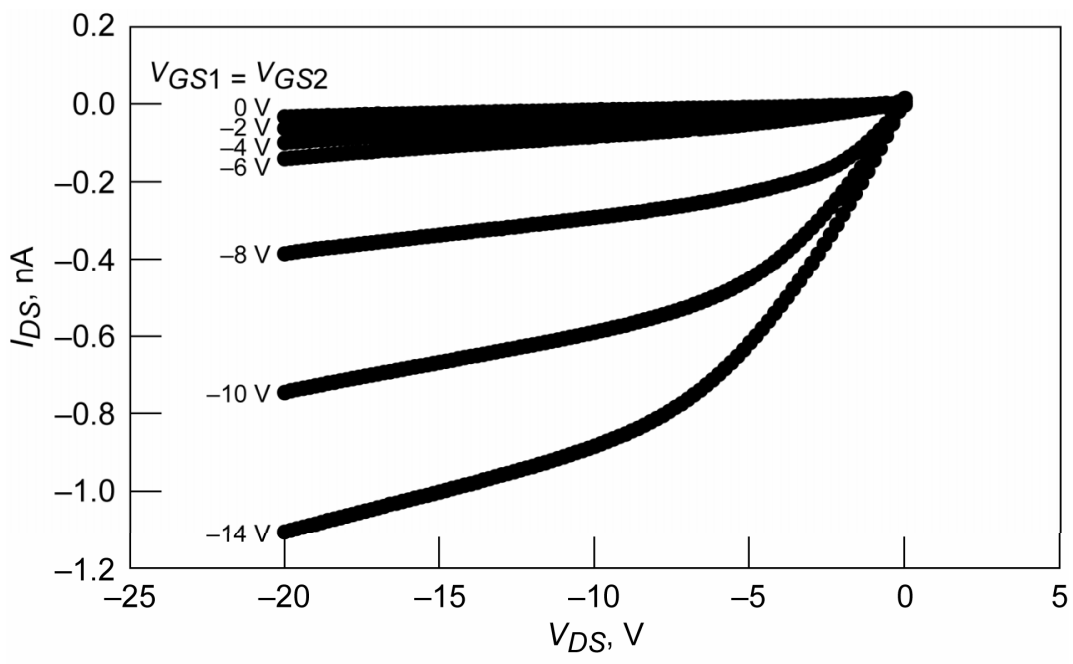

Figure 5.-Drain source current versus drain-source voltage $\left(I_{D S}-V_{D S}\right)$ characteristics of the split gate field effect transistor, where the gate-source voltages $\left(V_{G S} 1=V_{G S} 2\right)$ are as indicated.

gate bias conditions indicating some doping. The field effect charge mobility of this device was also calculated from the saturated section of the $I-V$ curves using the standard FET equation:

$$
I_{D S}=\frac{\mu Z C_{i}}{2 L}\left(V_{G S}-V_{T H}\right)^{2}
$$

where the various parameters have been defined earlier, and $V_{T H}$ represents the threshold voltage at which the conduction channel begins to be formed. Figure 6 shows the variation in the $I_{D S}$ versus $V_{G S}$ (with both the gates biased simultaneously to the same value) at a fixed drain-source voltage of $-20 \mathrm{~V}$. A corresponding plot of $I_{D S}{ }^{1 / 2}$ versus $V_{G S}$ is also shown in figure 6 from which we extract $V_{T H}=-8 \mathrm{~V}$ and the mobility as $5 \times 10^{-4} \mathrm{~cm}^{2} / \mathrm{V}$-s. Hysteresis effects are minimal although not totally absent as can be seen in figure 6 as the device was measured in vacuum and the shift in the threshold voltage was $1 \mathrm{~V}$. 


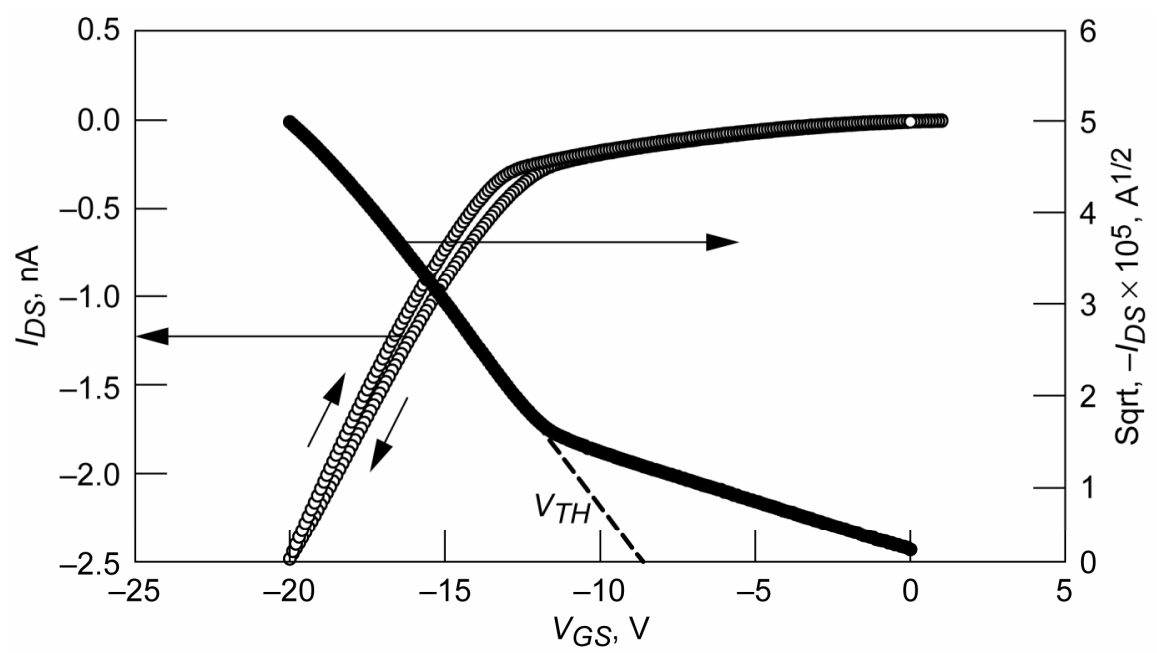

Figure 6.-Variation of drain-source current $\left(I_{D S}\right)$ as a function of gate-source voltage $\left(V_{G S}\right)$ with the drain-source voltage $\left(V_{D S}\right)$ held fixed at $-20 \mathrm{~V}$ (o). The corresponding plot of $I_{D S}{ }^{-1 / 2}$ versus. $V_{G S}$ is also shown $(\bullet)$ for increasing $V_{G S}$.

One application of the split-gate architecture for logic circuitry is demonstrated via a two-input logic AND circuit, shown schematically in the inset to figure 7. To create the device, a $10 \mathrm{M} \Omega$ load resistor was connected between ground and the transistor source terminal, with the two gate terminals serving as the inputs and the output $\left(V_{R}\right)$ was taken at the source terminal across the load resistor. A low frequency $(0.01 \mathrm{~Hz})$ square wave signal served as the input gate bias. For all combinations of $V_{G S 1}$ and $V_{G S 2}$ except $V_{G S 1}=V_{G S 2}=-10 \mathrm{~V}$, the transistor was in the resistive "OFF" state, and $-0.3 \mathrm{mV}<V_{R}<0 \mathrm{~V}$. For $V_{G S 1}=V_{G S 2}=-10 \mathrm{~V}$, the transistor was in the more conductive "ON" state, causing a greater portion of the voltage drop to occur across the load resistor. As a result, $V_{R}$ is a more negative value $\left(-2.0 \mathrm{mV}<V_{R}\right.$ $<-1.7 \mathrm{mV}$ ). The ability of the device to operate as an AND logic circuit is demonstrated in figure 7 . The upper graph shows $V_{G S 1}$ and $V_{G S 2}$ as a function of time while the lower graph shows the corresponding change in the output voltage $V_{R}$ as a function of time for the four possible combinations of $V_{G S 1}$ and $V_{G S 2}=0$ or $-10 \mathrm{~V}$. Larger outputs were observed only when both gates were simultaneously biased "high". Overshoots and undershoots in $I_{D S}$ were observed at the rising and falling edges of the gate bias due to the capacitive effects associated with sudden changes in the input signals. For practical applications, the magnitude of $V_{R}$ in the transistor "ON" ("OFF") state must be increased (decreased) i.e., the dynamic ratio $I_{\mathrm{ON}} / I_{\mathrm{OFF}}$ must be increased. This can be achieved via the use of purified starting materials, pretreated substrates to make them more hydrophobic and hence have better contact with the semiconductor (reduced charge trapping) and substrates that possess more planar channel topologies, either by embedding the gate electrodes deeper into the gate dielectric prior to CVD growth of the upper dielectric or by using a thicker CVD grown gate dielectric that will minimize step coverage problems. As a simple model, our results can be explained by treating the device as consisting of two gate voltage controlled switches connected in series and which lead to the logical AND operation via the ON/OFF operation of these switches. The phenomena described in this paper can also be extended to other types of logic devices. For example, connecting the load resistor at the drain terminal and tapping the output between the drain terminal and ground is predicted to have the effect of producing NAND logic operation for the corresponding input gate biases. 


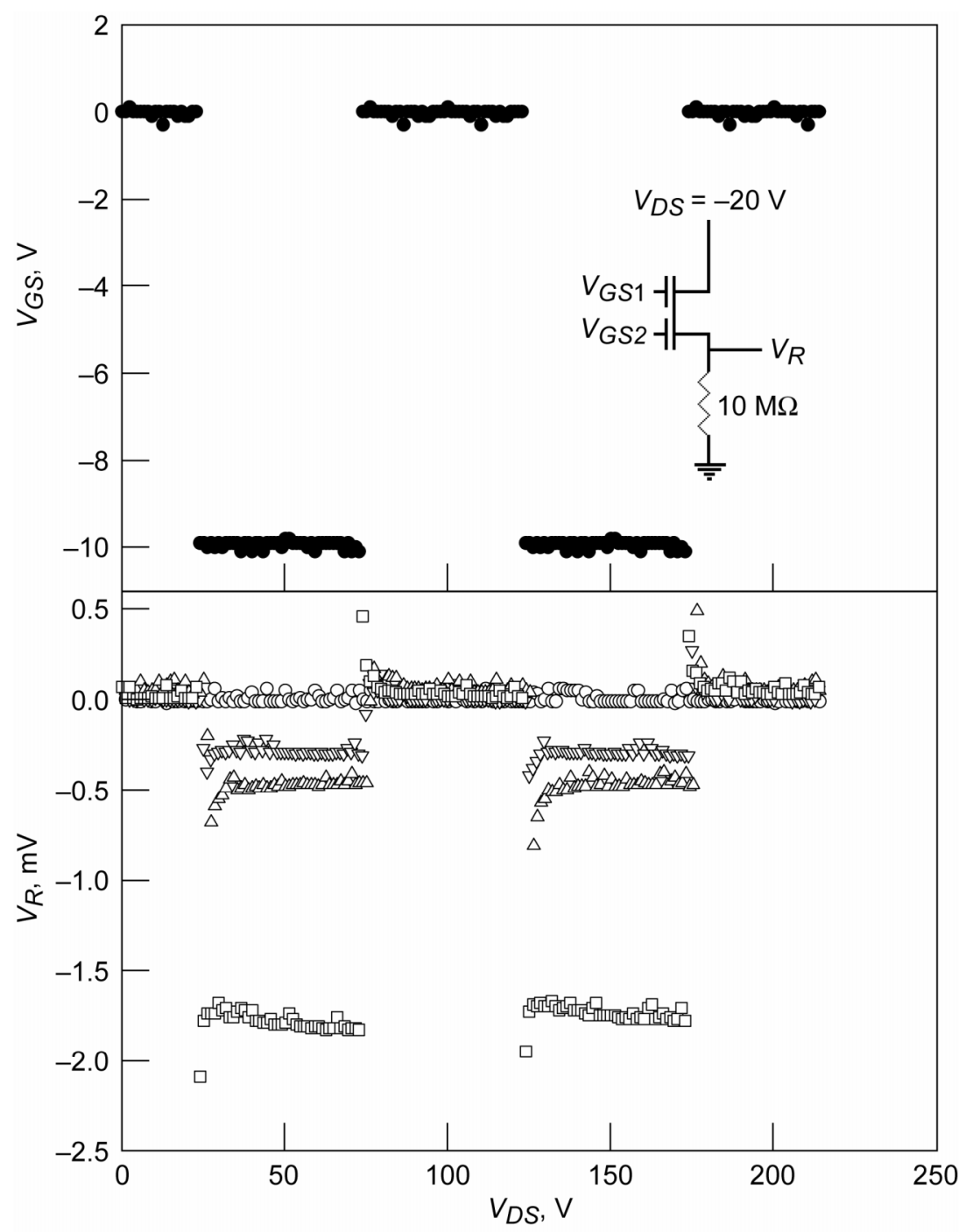

Figure 7.-Electrical performance of the split gate field effect transistor as a logic AND circuit. $V_{D S}$ was maintained constant at $-20 \mathrm{~V}$, and the output voltage $\left(V_{R}\right)$ was switched from $V_{\text {OFF }}(\sim 0 \mathrm{~V})$ to $V_{\mathrm{ON}}(\sim-2 \mathrm{mV})$ by applying $-10 \vee$ to both the gate electrodes simultaneously. The top graph shows $V_{G S 1}$ and $V_{G S 2}$ as a function of time, and the bottom plots show $V_{R}$ as a function of time. A gate voltage of $0 \mathrm{~V}$ corresponds to that gate being grounded. A schematic diagram of the logic AND circuit is shown as an inset in the top graph. The symbols in the bottom plot represent the following combinations for gate-source voltages $V_{G S 1}$ and $V_{G S 2}$ : $(\circ \rightarrow 0 \vee 0 \vee) ;\left(\nabla \rightarrow V_{G S} 0 \vee\right) ;\left(\Delta \rightarrow 0 \vee V_{G S}\right) ;\left(\square \rightarrow V_{G S} V_{G S}\right)$ 


\section{Summary}

A split-gate field effect transistor with a thin film of RRP3HT as the active semiconducting layer was fabricated and characterized. This device was seen to work as a dual input logic AND gate and was operated by applying either 0 or $-10 \mathrm{~V}$ to each of the gate electrodes. When $-10 \mathrm{~V}$ was simultaneously applied to both gates, the device was conductive, while any other combination of gate voltages rendered the device resistive. The AND circuit was formed by placing a $10 \mathrm{M} \Omega$ resistor between the source terminal and ground. The device also worked as a field effect transistor with a dynamic ratio of $\sim 30$ and had a charge carrier mobility of $5 \times 10^{-4} \mathrm{~cm}^{2} / \mathrm{V}$-s. These device parameters are expected to improve via the use of purified starting materials, pretreated substrates and more planar channel topography. A significant advantage of this device is that AND logic devices with multiple inputs can be built using a single RRP3HT channel with multiple gates.

\section{References}

1. J.-C. Chiang and A.G. MacDiarmid, Synth. Metals 13, 193 (1986).

2. Y. Cao, P. Smith, and A.J. Heeger, Synth. Metals 48, 91-97 (1992).

3. P.N. Adams, P.J. Laughlin, and A.P. Monkman, Solid State Commun. 91, 875-878 (1994). Tsumura, H. Koezuka, and T. Ando, Appl. Phys. Lett. 49, 1210 (1986).

4. J.H. Burroughes, C.A. Jones, and R.H. Friend, Nature 335, 137 (1988).

5. G. Horowitz, D. Fichou, X. Peng, and F. Garnier, Synth. Metals 41-43, 1127 (1991).

6. A.R. Brown, C.P. Jarret, D.M. de Leeuw, and M. Matters, Synth. Metals 88, 37 (1997).

7. T-An Chen, X. Wu, and R.D. Rieke, J. Am. Chem. Soc. 117, 233 (1995).

8. Z. Bao, A. Dodabalapur, and A.J. Lovinger, Appl. Phys. Lett. 69, 4108 (1996).

9. H. Sirringhaus, N. Tessler, and R.H. Friend, Science 280, 1741 (1998).

10. F. Garnier, R. Hajlaoui, A. Yassar, and P. Srivastava, Science 265, 1684 (1994). Dodabalapur, L. Torsi, and H.E. Katz, Science 268, 207 (1995).

11. J. Zaumseil, T. Someya, Z. Bao, Y.L. Loo, R. Cirelli, and J.A. Rogers, Appl. Phys. Lett. 82, 793 (2003).

12. M. Halik, H. Klauk, U. Zschieschang, T. Kriem, G. Schmid, W. Radik, and K. Wussow, Appl. Phys. Lett. 81, 289 (2002).

13. N.J. Pinto, A.T. Jonson Jr., A.G. MacDiarmid, C.H. Mueller, N. Theofylaktos, D.C. Robinson, and F.A. Miranda, Appl. Phys. Lett. 83, 4244 (2003).

14. R. Gonzalez and N.J. Pinto, Synth. Metals 151, 275 (2005). Babel, D. Li, Y. Xia, and S.A. Jenekhe, Macromolecules 38, 4705 (2005).

15. C.H. Mueller, N. Theofylaktos, F.A. Miranda, A.T. Johnson, Jr., and N.J. Pinto, Thin Solid Films 496, 494 (2006).

16. C. Dimitrakopoulos and P. Malenfant, Adv. Mat. 14, 99 (2002).

17. S. Scheinert and G. Paasch, Phys. Stat. Sol. (a) 6, 1263 (2004).

18. S. Hoshino, M. Yoshida, S. Uemura, T. Kodzasa, N. Takada, T. Kamata, and K. Yase, Appl. Phys. Lett. 95, 5088 (2004). 
Public reporting burden for this collection of information is estimated to average 1 hour per response, including the time for reviewing instructions, searching existing data sources, gathering and maintaining the data needed, and completing and reviewing the collection of information. Send comments regarding this burden estimate or any other aspect of this collection of information, including suggestions for reducing this burden, to Washington Headquarters Services, Directorate for Information Operations and Reports, 1215 Jefferson Davis Highway, Suite 1204, Arlington, VA 22202-4302, and to the Office of Management and Budget, Paperwork Reduction Project (0704-0188), Washington, DC 20503.

\begin{tabular}{|l|l|l}
\hline 1. AGENCY USE ONLY (Leave blank) & $\begin{array}{c}\text { 2. REPORT DATE } \\
\text { May } 2006\end{array}$ & $\begin{array}{r}\text { 3. REPORT TYPE AND DATES COVERED } \\
\text { Technical Memorandum }\end{array}$
\end{tabular}

4. TITLE AND SUBTITLE 5. FUNDING NUMBERS

Dual Input AND Gate Fabricated From a Single Channel Poly

(3-Hexylthiophene) Thin Film Field Effect Transistor

6. AUTHOR(S)

WBS 953033.01.03.06

N.J. Pinto, R. Pérez, C.H. Mueller, N. Theofylaktos, and F.A. Miranda

7. PERFORMING ORGANIZATION NAME(S) AND ADDRESS(ES)

8. PERFORMING ORGANIZATION REPORT NUMBER

National Aeronautics and Space Administration

John H. Glenn Research Center at Lewis Field

Cleveland, Ohio 44135-3191

E-15215

9. SPONSORING/MONITORING AGENCY NAME(S) AND ADDRESS(ES)

10. SPONSORING/MONITORING AGENCY REPORT NUMBER

National Aeronautics and Space Administration

Washington, DC 20546-0001

NASA TM-2006-214015

\section{SUPPLEMENTARY NOTES}

N.J. Pinto and R. Pérez, University of Puerto Rico-Humacao, Department of Physics and Electronics, Humacao, Puerto Rico 00791; C.H. Mueller, Analex Corporation, 1100 Apollo Drive, Brook Park, Ohio 44142; N. Theofylaktos and F.A. Miranda, NASA Glenn Research Center. Responsible person, F.A. Miranda, organization code RCA, 216-433-6589.

12a. DISTRIBUTION/AVAILABILITY STATEMENT 12b. DISTRIBUTION CODE

Unclassified - Unlimited

Subject Categories: 88 and 91

Available electronically at http://gltrs.grc.nasa.gov

This publication is available from the NASA Center for AeroSpace Information, 301-621-0390.

13. ABSTRACT (Maximum 200 words)

A regio-regular poly (3-hexylthiophene) (RRP3HT) thin film transistor having a split-gate architecture has been fabricated on a doped silicon/silicon nitride substrate and characterized. This device demonstrates AND logic functionality. The device functionality was controlled by applying either 0 or $-10 \mathrm{~V}$ to each of the gate electrodes. When $-10 \mathrm{~V}$ was simultaneously applied to both gates, the device was conductive $(\mathrm{ON})$, while any other combination of gate voltages rendered the device resistive (OFF). The p-type carrier charge mobility was about $5 \times 10^{-4} \mathrm{~cm}^{2} / \mathrm{V}$-sec. The low mobility is attributed to the sharp contours of the RRP3HT film due to substrate non-planarity. A significant advantage of this architecture is that AND logic devices with multiple inputs can be fabricated using a single RRP3HT channel with multiple gates.

14. SUBJECT TERMS

Poly (3-Hexylthiophene); Logic gate; JFET
15. NUMBER OF PAGES

15

16. PRICE CODE

\begin{tabular}{|c|c|c|}
\hline $\begin{array}{c}\text { 17. SECURITY CLASSIFICATION } \\
\text { OF REPORT } \\
\text { Unclassified }\end{array}$ & $\begin{array}{c}\text { 18. SECURITY CLASSIFICATION } \\
\text { OF THIS PAGE } \\
\text { Unclassified }\end{array}$ & $\begin{array}{c}\text { 19. SECURITY CLASSIFICATION } \\
\text { OF ABSTRACT } \\
\text { Unclassified }\end{array}$ \\
\hline
\end{tabular}

NSN 7540-01-280-5500

Standard Form 298 (Rev. 2-89)

Prescribed by ANSI Std. Z39-18 298-102 

